\title{
Potential health effects of Champagne wine consumption
}

Article

Accepted Version

Vauzour, D., Corona, G., Hercelin, J., Garnotel, R., Gillery, P., Lovegrove, J. A., Williams, C. M. and Spencer, J. P. E. (2011) Potential health effects of Champagne wine consumption. Journal of Wine Research, 22 (2). pp. 175-180. ISSN 14699672 doi: https://doi.org/10.1080/09571264.2011.603251 Available at https://centaur.reading.ac.uk/25329/

It is advisable to refer to the publisher's version if you intend to cite from the work. See Guidance on citing.

To link to this article DOI: http://dx.doi.org/10.1080/09571264.2011.603251

Publisher: Taylor \& Francis

All outputs in CentAUR are protected by Intellectual Property Rights law, including copyright law. Copyright and IPR is retained by the creators or other copyright holders. Terms and conditions for use of this material are defined in the End User Agreement.

\section{www.reading.ac.uk/centaur}

\section{CentAUR}

Central Archive at the University of Reading 
Reading's research outputs online 


\section{POTENTIAL HEALTH EFFECTS OF CHAMPAGNE WINE CONSUMPTION}

David Vauzour $^{\text {a, e, } 1 * \text {, Giulia Corona }}{ }^{\mathrm{a}, 1}$, Justine Hercelin ${ }^{\mathrm{a}}$, Roselyne Garnotel ${ }^{\mathrm{b}}$, Philippe Gillery $^{\mathrm{b}}$, Julie A Lovegrove ${ }^{\mathrm{c}}$, Claire M Williams ${ }^{\mathrm{d}}$ and Jeremy PE Spencer ${ }^{\mathrm{a}, \mathrm{c} *}$

${ }^{a}$ Molecular Nutrition Group, Department of Food and Nutritional Sciences, School of Chemistry, Food and Pharmacy, University of Reading, PO Box 226, Whiteknights, Reading RG6 6AP, UK.

b Laboratoire de Biochimie et Biologie Moléculaire, UFR Médecine, CNRS UMR 6237, IFR 53, 51 rue Cognacq-Jay 51095 Reims, France

${ }^{c}$ Hugh Sinclair Human Nutrition Group, School of Chemistry, Food and Pharmacy, University of Reading, Reading RG6 6AP, UK

${ }^{\mathrm{d}}$ School of Psychology and Clinical Language Sciences, University of Reading, Reading RG2 6AP, UK

${ }^{\mathrm{e}}$ Current address: School of Medicine, University of East Anglia, Norwich NR4 7TJ, UK

${ }^{1}$ These authors contributed equally to this work

* To whom correspondence should be addressed:

e-mail : D.Vauzour@uea.ac.uk ; j.p.e.spencer@reading.ac.uk 


\begin{abstract}
Epidemiological studies have suggested an inverse correlation between red wine consumption and the incidence of cardiovascular and neurodegenerative disorders. Although white wines are generally low in polyphenol content as compared to red wines, Champagne wines have been shown to contain relatively high amounts of phenolic acids that may exert protective cellular actions in vivo. In this study, we have investigated the potential cardioprotective and neuroprotective effects of Champagne wine. Our data suggest that a daily moderate consumption of Champagne wine may improve vascular performance via the delivery of phenolic constituents capable of improving NO bioavailability and the modulation of metalloproteinase. Moreover, Champagne wine intervention significantly increased spatial working memory in aged animals, whilst no improvement was observed in presence of alcohol. Together, these data suggest that polyphenols present in Champagne wine may induce cardioprotective and neuroprotective effects, delaying the onset of degenerative disorders.
\end{abstract}

Keywords: Champagne wine, cardiovascular disease, working spatial memory, polyphenols, brain 


\section{Introduction}

Epidemiological studies have suggested an inverse correlation between the consumption of red wine and the incidence of cardiovascular disease and neurological disorders (Di Castelnuovo et al., 2002; Orgogozo et al., 1997). This protection, is mainly believed to be mediated by the ability of polyphenols present in the wine to exert anti-inflammatory properties (Rice-Evans and Miller, 1996) and to modulate signalling cascades that regulate nitric oxide production (Bastianetto, 2002) and neuronal survival (Schroeter et al., 2002). Although white wines are generally low in polyphenol content, in particular flavonoids, compared to red wines, Champagne wine has been shown to contain relatively high amounts of phenolic compounds (Vauzour et al., 2010). Moderate Champagne wine consumption has been shown to exert a number of effects in vivo, effecting peripheral serotonin and dopamine release (Boyer et al., 2004) and increasing plasma vitamin A concentration (Cartron et al., 2003). Champagne wine polyphenols have also be shown to protect cells against injury induced by peroxynitrite (Vauzour et al., 2007a), a physiologically relevant oxidizing species which has been implicated in vascular wall pathology (van der Loo et al., 2000) and neurodegeneration (Szabo et al., 2007). However, thus far, there have been no studies investigating its consumption and changes in endothelial function and thus cardiovascular risk or improvement in memory. In the present studies, we have performed a human intervention trial in order to assess whether acute, moderate Champagne wine consumption is capable of modulating endothelial function in healthy human volunteers. Since improvements in blood flow in the brain may impact on memory in a number of ways (i.e increasing the delivery of oxygen to specific brain regions), we have also performed an animal study aiming at investigating the effects of a chronic Champagne wine intervention on spatial working memory. Together our data suggest that moderate Champagne wine consumption may help to improve both cardiovascular and dementia risks. 


\section{Materials and Methods}

Human intervention: The study was conducted according to the guidelines laid down in the Declaration of Helsinki. Fifteen healthy male and female subjects were recruited from the University of Reading and surrounding area. The study was designed as a single blind, randomized, crossover intervention trial, where volunteers were asked to consume either 375 $\mathrm{ml}$ of Champagne wine (Chardonnay, Pinot Noir and Pinot Meunier, 12\% alcohol) or a control matched for alcohol content, fruit sugars and acids. Subjects were randomly assigned to either the Champagne wine or control group and asked to consume the beverage within a 10 min period. Peripheral micro-vascular function was assessed by Laser Doppler imaging with iontophoresis (LDI), a validated technique which quantifies the vasodilator responses to $1 \%$ acetylcholine (ACh, endothelium dependent vasodilatation) and $1 \%$ sodium nitroprusside (SNP, endothelial independent vasodilatation), delivered trans-dermally. Following a washout period of 28 days, volunteers returned to the unit to complete the second arm of the study where the procedure above was repeated. Metalloproteinase were analyzed by gelatine zymography as previously described (Buache et al., 2007). All biochemical parameters were assayed on an ILAB 600 chemistry analyzer (Instrumentation Laboratory, Warrington, UK) using enzyme based colorimetric tests supplied by Instrumentation Laboratory. Total Oxidative Capacity (TOC) was determined by a rapid enzymatic in vitro diagnostic assay obtained from Tatzber KEG (Höflein at the Danube, Austria).

Animal study: 3 groups of adult, male Wistar rats ( $\mathrm{n}=8$ per group; Charles-River, France) were housed under a 12:12 light:dark cycle. All procedures were conducted according to the specifications of the United Kingdom Animals (Scientific Procedures) Act, 1986. The three intervention diets (placebo, ethanol 12\% and Champagne wine (Chardonnay, Pinot Noir and Pinot Meunier, 12\% alcohol)) used were analytically well characterized and contained a defined and characterized amount of phytochemicals and were as far as possible macro- and 
micronutrient-matched. Rats were tested in a cross-maze apparatus as described previously (Williams et al., 2008). Rats were given 3 test sessions on the cross-maze, one session administered immediately before supplementation was started (baseline), subsequent sessions were administered at 3 and 6 weeks. Following completion of the test, animals were sacrificed and brains were removed and hippocampal and cortical regions were dissected, snap-frozen in liquid nitrogen and stored at $-80^{\circ} \mathrm{C}$ until analysis. Levels of proteins were assessed by Western immunoblotting as described previously (Vauzour et al., 2007b)

\section{Results and Discussion}

\section{Champagne wine promotes endothelium-independent vascular reactivity}

Many epidemiological studies have suggested that a daily and moderate consumption of red or white wine is associated with a lower incidence of cardiovascular disease (Renaud and de Lorgeril, 1992). Many of the effects of red wine are compatible with the action of winederived polyphenols on endothelium-derived nitric oxide ( $\mathrm{NO}^{*}$ ) production (Flesch et al., 1998), whilst the white wine effects may result from the synergistic actions of polyphenols and other phenolic constituents on LDL oxidation and platelet function (Pignatelli et al., 2006). In the present study, we show that Champagne wine consumption is capable of inducing acute vascular effects and in modifying levels of specific vascular active components. Indeed, consumption of Champagne wine was observed to induce an acute change in endothelium-independent vasodilatation at 4 and 8 hours post consumption $(\mathrm{p}=$ 0.045 and $p=0.037$ respectively), whilst the alcohol matched control did not induce any changes in vascular reactivity. Although both Champagne wine $(\mathrm{p}=0.030)$ and the control $(\mathrm{p}=$ 0.045) induced an increase in endothelium-dependent vascular reactivity at $4 \mathrm{~h}$, there was no significant difference between the vascular effects induced by Champagne wine or the control. These observations are in agreement with previous studies which indicate that 
moderate alcohol is capable of inducing an acute increase in blood flow in an endotheliumdependent manner (Tawakol et al., 2004; Vlachopoulos et al., 2003). However, we found that only the Champagne wine intervention was capable of significantly inducing an increase in endothelium-independent vasodilatation, which was maintained up to $8 \mathrm{~h}$ post consumption. These data suggest that moderate Champagne wine consumption may enhance microvascular blood flow for a sustained period, through maintenance of local nitric oxide levels, in this case delivered via iontophoresis. These effects were also accompanied by an acute decrease in the concentration of matrix metalloproteinase MMP-9 $(1 \mathrm{~h} ; \mathrm{p}<0.05)$, a significant decrease in the plasma levels of oxidising species $(6 \mathrm{~h} ; \mathrm{p}<0.05)$ and an increase in urinary excretion of a number of phenolic metabolites. In particular, the mean total excretion of hippuric acid, protocatechuic acid and isoferulic acid were all significantly greater following the Champagne wine intervention compared to control intervention $(\mathrm{p}<0.001)$. These phenolic metabolites may affect vascular function by improving local nitric oxide bioavailability by two potential mechanisms. Firstly, they may increase the local half-life of NO via reaction with reactive oxygen species, such as superoxide (Radi et al., 2001). Secondly, phenolic metabolites, such as those excreted post Champagne wine consumption, may mimic NADPH oxidase inhibitors (Steffen et al., 2007), such as apocynin thereby reducing the cellular production of superoxide and increasing the half-life of $\mathrm{NO}^{\circ}$, without any change in the rate of $\mathrm{NO}^{\circ}$ synthesis (Schewe et al., 2008). Our data suggest that a daily moderate consumption of Champagne wine may improve vascular performance via the delivery of phenolic constituents capable of improving nitric oxide bioavailability and reducing matrix metalloproteinase activity.

\section{Champagne wine improves working spatial memory}

Epidemiological studies have suggested that moderate wine consumption may reduce the incidence of certain age-related neurological disorders including Alzheimer's disease 
(Orgogozo et al., 1997). Polyphenols may act to protect the brain in a number of ways, including by protection of vulnerable neurons, the enhancement of existing neuronal function or by stimulating neuronal regeneration (Youdim and Joseph, 2001). For example, red wine antioxidants were observed to protect hippocampal neurons against ethanol-induced damage (Assuncao et al., 2007) and a moderate consumption of Cabernet Sauvignon attenuated A $\beta$ neuropathology in a mouse model of Alzheimer's disease (Wang et al., 2006). There is also a growing interest in the potential of polyphenols to improve memory, learning and general cognitive ability (Vauzour et al., 2008). In this study, we have investigated the effects of a chronic Champagne wine intervention on spatial working memory in aged animals (18 months), and have determined the molecular changes in the brain underlying these behavioural changes. The results indicated that Champagne wine intervention significantly increased spatial working memory in aged animals by $24.5 \pm 3.4 \%(\mathrm{p}<0.01)$, whilst no improvement was observed in presence of alcohol $(\mathrm{p}>0.05)$. Such observations are in agreement with previous studies demonstrating that chronic consumption of red wine unlike the ethanol solution alone, did not lead to a decline in hippocampal-dependent spatial memory (Assuncao et al., 2007). However, Champagne wine, which is low in flavonoids, was also observed to improve spatial working memory. Such effects may be the result of other phytochemicals such as hydroxycinnamates, phenolic acids and phenol alcohol. We have previously reported the beneficial effect of such molecules in primary cortical neurons challenged with 5-S-cysteinyl-dopamine (Vauzour et al., 2010) and peroxynitrite (Vauzour et al., 2007a). Moreover, for any polyphenol to exert direct neuroprotective actions they must also undergo permeation of the blood brain barrier (BBB), something that has been reported for both flavonoids and hydroxycinnamates (Youdim et al., 2004). However, whilst the ability of flavonoids to cross the BBB is believed to be dependent on lipophilicity, small phenolics are thought to transverse the BBB via amino acid transporters, such as has been 
reported for 4-ethylcatechol (Meiergerd and Schenk, 1994). Furthermore, caffeic acid shares structural similarities with L-DOPA and, as such, may undergo BBB transport via catecholamine transporter systems.

In order to investigate the mechanisms underlying Champagne wine actions in the brain, we have assessed widespread changes in hippocampal and cortical protein expressions in response to the various interventions. Changes in the number of, and strength of, connections between neurons, via their specific interactions with the MAPK pathways, leading to an increase in neurotrophins such as BDNF through CREB activation were observed. It is well reported that flavonoids may exert cellular action by interacting with the PI 3-kinase, Akt/PKB and MAP kinase signalling pathways (Schroeter et al., 2002). Smaller phenolics, such as caffeic acid or tyrosol, may also participate in cellular interactions of this nature (Nardini et al., 2000), or may directly react with toxic intermediates, as has been observed for p-coumaric acid (Kerry and Rice-Evans, 1999). All together, these processes act to maintain the number and quality of synaptic connections in the brain, a factor known to be essential for efficient long term potentiation (LTP), synaptic plasticity and ultimately the efficient working of memory.

\section{Acknowledgements}

Financial support for this work was from the Medical Research Council (Grant number: G0400278/NI02). Funding by the Biotechnology and Biological Sciences Research Council (BB/F008953/1; BB/E023185/1; BB/G005702/1) and the European Union (FP7 FLAVIOLA) are also acknowledged. 


\section{Bibliography}

Assuncao, M., Santos-Marques, M. J., De Freitas, V., Carvalho, F., Andrade, J. P., Lukoyanov, N. V. and Paula-Barbosa, M. M. (2007) Red wine antioxidants protect hippocampal neurons against ethanol-induced damage: A biochemical, morphological and behavioral study, Neuroscience, 146:4, pp. 1581-1592

Bastianetto, S. (2002) Red wine consumption and brain aging, Nutrition, 18:5, pp. 432-433

Boyer, J. C., Bancel, E., Fabbro Perray, P., Pouderoux, P., Balmes, J. L. and Bali, J. P. (2004) Effect of Champagne compared to still white wine on peripheral neurotransmitter concentrations., International Journal for Vitamin and Nutrition Research, 74:5, pp. 264-271

Buache, E., Garnotel, R., Aubert, D., Gillery, P. and Villena, I. (2007) Reduced secretion and expression of gelatinase profile in Toxoplasma gondii-infected human monocytic cells, Biochemical and Biophysical Research Communications, 359:2, pp. 298-303

Cartron, E., Fouret, G., Carbonneau, M. A., Lauret, C., Michel, F., Monnier, L., Descomps, B. and Léger, C. L. (2003) Red-wine beneficial long-term effect on lipids but not on antioxidant characteristics in plasma in a study comparing three types of wine - Description of two $O$-methylated derivatives of gallic acid in humans., Free Radical Research, 37:9, pp. $1021-1035$

Di Castelnuovo, A., Rotondo, S., Iacoviello, L., Donati, M. B. and De Gaetano, G. (2002) Meta-analysis of wine and beer consumption in relation to vascular risk, Circulation, 105:24, pp. 2836-2844 
Flesch, M., Schwarz, A. and Bohm, M. (1998) Effects of red and white wine on endotheliumdependent vasorelaxation of rat aorta and human coronary arteries, American Journal of Physiology, 275:4 Pt 2, pp. H1183-1190

Kerry, N. and Rice-Evans, C. (1999) Inhibition of peroxynitrite-mediated oxidation of dopamine by flavonoid and phenolic antioxidants and their structural relationships, Journal of Neurochemistry, 73:1, pp. 247-253

Meiergerd, S. M. and Schenk, J. O. (1994) Striatal transporter for dopamine: catechol structure-activity studies and susceptibility to chemical modification, Journal of Neurochemistry, 62:3, pp. 998-1008

Nardini, M., Scaccini, C., Packer, L. and Virgili, F. (2000) In vitro inhibition of the activity of phosphorylase kinase, protein kinase $\mathrm{C}$ and protein kinase $\mathrm{A}$ by caffeic acid and a procyanidin-rich pine bark (Pinus marittima) extract, Biochimica et Biophysica Acta, 1474:2, pp. $219-225$

Orgogozo, J., Dartigues, J., Lafon, S., Letenneur, L., Commenges, D., Salomon, R., Renaud, S. and Breteler, M. (1997) Wine consumption and dementia in the ederly: a prospective community study in the Bordeaux area., Revue Neurologique (Paris), 153, pp. 185-192

Pignatelli, P., Ghiselli, A., Buchetti, B., Carnevale, R., Natella, F., Germano, G., Fimognari, F., Di Santo, S., Lenti, L. and Violi, F. (2006) Polyphenols synergistically inhibit oxidative stress in subjects given red and white wine, Atherosclerosis, 188:1, pp. 77-83

Radi, R., Peluffo, G., Alvarez, M. N., Naviliat, M. and Cayota, A. (2001) Unraveling peroxynitrite formation in biological systems, Free Radical Biology and Medicine, 30:5, pp. $463-488$ 
Renaud, S. and de Lorgeril, M. (1992) Wine, alcohol, platelets, and the French paradox for coronary heart disease, Lancet, 339:8808, pp. 1523-1526

Rice-Evans, C. A. and Miller, N. J. (1996) Antioxidant activities of flavonoids as bioactive components of food, Biochemical Society Transactions, 24:3, pp. 790-795

Schewe, T., Steffen, Y. and Sies, H. (2008) How do dietary flavanols improve vascular function? A position paper, Archives of Biochemistry and Biophysics, 476:2, pp. 102-106

Schroeter, H., Boyd, C., Spencer, J. P., Williams, R. J., Cadenas, E. and Rice-Evans, C. (2002) MAPK signaling in neurodegeneration: influences of flavonoids and of nitric oxide, Neurobiology of Aging, 23:5, pp. 861-880

Steffen, Y., Schewe, T. and Sies, H. (2007) (-)-Epicatechin elevates nitric oxide in endothelial cells via inhibition of NADPH oxidase, Biochemical and Biophysical Research Communications, 359:3, pp. 828-833

Szabo, C., Ischiropoulos, H. and Radi, R. (2007) Peroxynitrite: biochemistry, pathophysiology and development of therapeutics, Nature Reviews Drug Discovery, 6:8, pp. $662-680$

Tawakol, A., Omland, T. and Creager, M. A. (2004) Direct effect of ethanol on human vascular function, American Journal of Physiology - Heart and Circulatory Physiology, 286:6, pp. H2468-2473

van der Loo, B., Labugger, R., Skepper, J. N., Bachschmid, M., Kilo, J., Powell, J. M., Palacios-Callender, M., Erusalimsky, J. D., Quaschning, T., Malinski, T., Gygi, D., Ullrich, V. and Luscher, T. F. (2000) Enhanced peroxynitrite formation is associated with vascular aging, Journal of Experimental Medicine, 192:12, pp. 1731-1744 
Vauzour, D., Corona, G. and Spencer, J. P. (2010) Caffeic acid, tyrosol and p-coumaric acid are potent inhibitors of 5-S-cysteinyl-dopamine induced neurotoxicity, Archives of Biochemistry and Biophysics, 501:1, pp. 106-111

Vauzour, D., Vafeiadou, K., Corona, G., Pollard, S. E., Tzounis, X. and Spencer, J. P. (2007a) Champagne wine polyphenols protect primary cortical neurons against peroxynitriteinduced injury, Journal of Agricultural and Food Chemistry, 55:8, pp. 2854-2860

Vauzour, D., Vafeiadou, K., Rice-Evans, C., Williams, R. J. and Spencer, J. P. (2007b) Activation of pro-survival Akt and ERK1/2 signalling pathways underlie the anti-apoptotic effects of flavanones in cortical neurons, Journal of Neurochemistry, 103:4, pp. 1355-1367

Vauzour, D., Vafeiadou, K., Rodriguez-Mateos, A., Rendeiro, C. and Spencer, J. P. (2008) The neuroprotective potential of flavonoids: a multiplicity of effects, Genes \& Nutrition, 3:34, pp. $115-126$

Vlachopoulos, C., Tsekoura, D., Tsiamis, E., Panagiotakos, D. and Stefanadis, C. (2003) Effect of alcohol on endothelial function in healthy subjects, Vascular Medicine, 8:4, pp. 263-265

Wang, J., Ho, L., Zhao, Z., Seror, I., Humala, N., Dickstein, D. L., Thiyagarajan, M., Percival, S. S., Talcott, S. T. and Pasinetti, G. M. (2006) Moderate consumption of Cabernet Sauvignon attenuates A beta neuropathology in a mouse model of Alzheimer's disease, Faseb Journal, 20:13, pp. 2313-2320

Williams, C. M., El Mohsen, M. A., Vauzour, D., Rendeiro, C., Butler, L. T., Ellis, J. A., Whiteman, M. and Spencer, J. P. (2008) Blueberry-induced changes in spatial working memory correlate with changes in hippocampal CREB phosphorylation and brain-derived neurotrophic factor (BDNF) levels, Free Radical Biology and Medicine, 45:3, pp. 295-305 
Youdim, K. A. and Joseph, J. A. (2001) A possible emerging role of phytochemicals in improving age-related neurological dysfunctions: a multiplicity of effects, Free Radical Biology and Medicine, 30:6, pp. 583-594

Youdim, K. A., Qaiser, M. Z., Begley, D. J., Rice-Evans, C. A. and Abbott, N. J. (2004) Flavonoid permeability across an in situ model of the blood-brain barrier, Free Radical Biology and Medicine, 36:5, pp. 592-604 